\title{
Метафора systema digestorium в русском лингвокультурном пространстве
}

\author{
The metaphor systema digestorium \\ in the Russian linguocultural space
}

\begin{abstract}
In recent years linguistic studies have laid great emphasis on the semantic side of linguistic expressions. The aim of this paper is to introduce and describe 'systema digestorium' viewed from the perspective of the conceptual metaphor in Russian. It describes the process of creating such metaphors based on the notions of source and target domains. From a linguistic point of view, an interest arises to answer the question of how the functioning of such an important organ as the digestive system is reflected in the conceptualization of the surrounding world. This issue is important because the metaphorization is based on the use of everyday human experience, reflecting processes known to all human kind, including those of a physiological nature. The research material was taken from the national corpus of the Russian language and a number of dictionaries. The figurative meaning of activities related to grinding, swallowing, digesting food, as well as excreting food debris became the object of the research. The basic identifiers are the verbs: to chew, to swallow, to digest, to defecate. Each stage of the digestive system has its own specificity and concentrates on specific parts in viewing the world. In addition, the metaphor 'systema digestorium' is often used in Russian linguaculture to convey the expressiveness and originality of a language.
\end{abstract}

Keywords: conceptual metaphor, Russian verbs, semantics, digestive system

Andrzej Narloch, Uniwersytet im. Adama Mickiewicz w Poznaniu, Poznań - Polska, andrzej. narloch@amu.edu.pl, ORCID ID: https://orcid.org/0000-0001-5225-289X

Пищеварительная система (лат. systema digestorium) - это совокупность органов пищеварения, представленная ротовой полостью, глоткой, пищеводом, желудком, кишечником и вспомогательными органами. Пищеварительная система в жизнедеятельности человека играет исключительную роль, ведь за счет питания организм обеспечивается энергией и питательными веществами.

Пища в любом культурном пространстве ассоциируется, с одной стороны, с чем-то необходимым для восполнения потребностей организма, его 
жизненно-биологических функций, с другой - с каким-либо вкусовым ощущением, возникающим в результате действия различных веществ на рецепторы вкуса.

С лингвистической точки зрения интерес представляет вопрос о том, каким образом функционирование таких важных органов отражается в концептуализации окружающего мира. Данный вопрос весьма существенен, так как в основе метафоризации лежит использование жизненного опыта, отражающего известные человеку процессы, в том числе физиологического характера.

В настоящей статье нами будут рассмотрены избранные лингвокультурологические аспекты метафоры пищеварительной системы человека. Экземплификационный материал был взят из различных словарей и Национального корпуса русского языка (NKRÂ). Объектом данного исследования являются переносные значения слов, устойчивые и фразеологические единицы. В свою очередь, цель настоящей статьи заключается в представлении функционирования данной системы и ее роли в аспекте национально-специфической картины мира. Поэтому исключительно важным остается ответ на вопрос, как данная система переосмысляется и какие семантические поля она обслуживает в процессе метафоризации. Выбор данной темы мотивирован ее антропоцентричностью, поскольку в центре ее внимания находится человек и обеспечение его жизнедеятельности.

Лексический блок лексем, охватывающий процессы systema digestorium, представляется рядом глаголов, семантически связанных с действиями:

1. измельчения/пережевывания: кусать, грызть, жевать;

2. проглатывания: проглотить;

3. переваривания: переварить;

4. выведения: испражняться.

В основе данных глаголов лежит семантика физиологического действия, описанная базовыми глаголами-идентификаторами: кусать, глоmaть, переваривать, испражняться ${ }^{1}$. Грамматически данные глаголы отличаются объектной валентностью (кроме последнего) с указанием на предмет действия.

Анализ значений слов, согласно Ришарду Токарскому, отражает одновременно человеческое мировоззрение и категоризацию отдельных фрагментов мира. При этом важно выявить структуры целых лексических блоков с учетом их значения и взаимосвязей между отдельными элемен-

${ }^{1}$ В настоящем изложении исключаются из анализа глаголы ecms, numь и их близкие синонимы (кушать, потчевать, хлебать и т. д.), поскольку их семантика непосредственно не связана с процессами пищеварения, а лишь с потреблением питания. 
тами, что, в свою очередь, покажет их объективный и регулярный характер (Tokarski 35-36). Более того, каждый язык по-своему категоризирует окружающее человека пространство (Maslova 64), т. е. человеческий мозг членит пространство на определенные отрезки, например, на то, что перед нами, за нами, над нами или под нами. Такой подход становится базой для образования ориентационных метафор. Джордж Лакофф и Марк Джонсон указывают также и на другие способы концептуализации мира в рамках замкнутых частей пространства. Такое понимание пространства позволяет говорить о понятии „вместилища”, или „контейнера”, которое реализуется в рамках метафоры пространства (Lakoff, Džonson 54). Как замечает Елена Самойловна Кубрякова,

понятие контейнера нередко используется как самоочевидное и редко дефинируется. Между тем хотя оно, действительно, выступает прежде всего как понятие, связанное с телесным и довольно простым опытом человека, за ним стоит далеко не простая структура знания, которую в известном смысле надлежит реконструрировать (Kubrâkova 480).

Понятие „контейнера” играет важную роль в процессе членения мира и реконструкции языковой картины мира, в которой отражается жизненный опыт этноса, его ценности, способ видения и оценки мира. Важно отметить, что в собранном материале реализуется также и этот тип метафор. Предлагаемая нами схема анализа метафорических выражений systema digestorium учитывает четыре уровня данной системы, которые описаны ниже.

1. Начальный этап подготовки (измельчения) питания. Данный этап представлен глаголами: кусать, грызть, жевать. В ротовой полости наступает прием пищи и ее первичная обработка, заключающаяся в механическом измельчении и начальном этапе переваривания. Механическое воздействие, связанное с измельчением, разбиением на мелкие части, а следовательно, и физическим уничтожением их начальной структуры, предопределяет, согласно нашему мнению, направление развития переносных смыслов. Примером может служить глагол грызть. Данный глагол в сочетании с абстрактными существительными, выражающими эмоции или мысли, получает переносное значение 'терзать, мучить, тревожить (о мыслях, чувствах и т. д.)’ (BTSRÂA 232). Ср. коллокации: кого-то грызет совесть (беспокойство, тоска) или кого-то грызет червь сомнения, тоска (печаль) грызет сердие, что-то грызет сердиее. Развитие данной семантики имеет свои корни в ежедневном опыте человека. В данном случае последовательно наблюдается одушевление, заключающееся в наделении абстрактного понятия свойствами живых существ. Следует также привести коллокацию угрызения совести, первый компонент которой словообразовательно связан с глаголом грызть. 
На базе значения 'убивать путем разрезания зубами глотки' у глагола грызть появились переносные: 'атаковать кого-л.', 'сильно вредить кому-л.', 'сильно ссориться'. Ср.: В мире, где люди грызут друг другу глотки за любую мелочь, он предпочел заботиться о других; Можно сказать, что это тот случай, когда не глотку ближнему грызть нужно, а гранит науки; Мы очень богатые, большие и добрые, и мы не будем грызть глотку соседу за наживу и прибыль; Это все, конечно, красиво про кооперацию. Но мы ведь, даже если трактор купим сообща, потом глотки перегрызем друг другу, кому первому на нем работать. Мы же за землю друг другу глотки грызем, пайщиков переманиваем. Глагол грызть развил также переносное значение 'медленно уничтожать что-л.', выдвигая на первый план семантику разбиения, разрушения объекта, ср.: Лед достигает воды, и соленые волны принимаются грызть его снизу. Таким образом, в данном случае образуется метафорическая модель „дробить (или рвать) что-л. - это уничтожать, портить что-л.".

Сферу ментальных понятий охватывает фразеологическая конструкция кусать (грызть) локти 'жалеть о чем-л., безнадежно утраченном, упущенном', ср.: А потом будете локти кусать, когда над вами вся академия станет потешаться; От досады на самого себя Иван готов был грызть локти. Проанализируем выражение грызть землю, которое функционирует в русском языке со значением 'стараться, добиваться чего-то изо всех сил'. При этом стоит указать на крайнюю степень интенсивности осуществления действия, ср.: Зубами буду грызть землю, но план по протоколам выполню. Возможно, что на базе этой конструкции появилось вторичное грызть горло в том же значении, ср.: „Я готова грызть горло всем”: жена рассказала о критическом состоянии осужденного в США Ярошенко. Наконец, приведем еще крылатую фразу - грызть гранит науки, получившую шутливый оттенок, со значением 'упорно, настойчиво учиться, овладевать знаниями' (BTSRÂA 232), где учеба представлена как процесс дробления, а знания как гранит, который в сознании людей ассоциируется с чем-то очень твердым, трудно поддающимся обработке. Благодаря метафоризации, нами получена выразительная и экспрессивная конструкция, представляющая усвоение знаний в рамках длительного и трудоемкого процесса.

Ротовая полость выполняет важные функции у человека, например измельчение пищи. Она также является частью артикуляционного аппарата, где генерируются звуки, складывающиеся в речь человека. Ее понимание в категориях вместилища (контейнера), которое можно заполнить, опорожнить, инициирует ряд метафор пространства. Наполненный рот осмысляется человеком в качестве препятствия, мешающего речевой активности, ср.: набрать в рот водыр; как (будто, словно, точно, ровно) воды в рот набрал 'прост. упорно 
молчать'. Синонимическое значение несет также прикусить (закусить) язык (язычок) ‘разг. спохватившись, внезапно замолчать' (BTSRÂ 981).

Фактографический материал показал, что ряд конструкций отличается стилистической окрашенностью. Например, выражение навязнуть в зубах несет семантику 'сильно надоесть' и употребляется в просторечии, ср.: Ваши поучения в зубах навязли! Интенсификация негативных коннотаций имеется во фразеологизме хлопот/забот полон рот у кого со значением 'разг. очень много дел, работы (при выполнении чего-либо важного)', ср.: С приездом внуков у бабушки был хлопот полон рот. В данном выражении хлопоты/заботы концептуализируются как еда, полностью заполняющая рот и мешающая правильному глотанию. Из этого следует, что в ряде контекстов наличие в чрезмерном объеме пищи во рту оценивается отрицательно.

Еда также осмысляется в рамках интеллектуальной активности - это продукт, который можно измельчить, приготовив его для проглатывания, подобно мыслям, которые следует разбить на меньшие единицы, для того чтобы они стали понятней. Судя по всему, это происходит на базе метафорической модели „мелкий (простой по структуре) ↔ понятный, крупный (сложный по структуре) $\leftrightarrow$ непонятный”. Такой перенос отражается в устойчивом обороте разжевывать (разжевать) и в рот положить 'подробно растолковать, объяснять в самой доступной форме что-либо' (FSRÂ 381), ср.: Baм, как первоклассникам, нужно все разжевать и в рот положить!

Изучаемые метафоры подтверждают суждения многих языковедов, что человек использует метафорический вектор от конкретного к абстрактному для освоения и понимания окружающего мира. Фразеологические единицы отражают действительность специфическим образом и избирательно. По словам Татьяны Алексеевны Зуевой,

это обусловлено, прежде всего, особенностями знаковой природы данных номинативных единиц языка: оценочностью, экспрессивностью их значения, в основу которого положены прототипические жизненные ситуации, отражающие культурно маркированные стереотипные представления носителей языка о том или ином фрагменте действительности (Zueva 103).

Процесс жевания может осмысляться также в других сферах человеческой активности. Владимир Станиславович Елистратов отмечает в русском арго выражение языки жевать, имеющее значение 'мямлить, быть в рассеянности, нерешительности’ (SRA 134). Таким образом, семантика глагола реализуется в бихевиористической и эмоциональной плоскостях. Интересно отметить также выражение жевать в разбивку, которое было отмечено Елистратовым в русском арго со значением 'говорить четче, не торопясь, 
делать паузы' (SRA 94). В таком случае процесс жевания уподобляется речевой активности ввиду внешнего подобия жевания и речи.

Разговорное выражение попадать на зубок (зуб) кому в значении 'становиться объектом насмешек, сплетен' концептуализирует объект действия в сфере пищеварительной системы, который поддается обработке, т. е. измельчению ${ }^{2}$. Данный фразеологизм отражает модель „поддавать разжевыванию - поддавать насмешкам".

В русском языке фразеологизм слюнки текут имеет значение 'кто-либо испытывает сильное желание попробовать, съесть или выпить что-либо, обычно вкусное' (FSRÂ 437). Однако семантика данного выражения изменилась и охватывает ситуации, в которых человек испытывает сильное, страстное желание приобрести что-либо заманчивое. Таким образом, первичное значение сильного желания съесть что-либо расширилось и определяет в широком смысле контексты, связанные с семантикой сильного желания, ср.: Почему у мужчин текут слюнки на красивых девушек?

Суммируя сказанное, отметим, что такие понятия, как проблемы, помехи, мысли, знания концептуализируются в сознании носителей в качестве еды, поддающейся процессу дробления. В отмеченных конструкциях процесс измельчения продукта метафорически выражается в сознании носителей русского языка в рамках активного воздействия на объект, с одной стороны, с целью его освоения, с другой - уничтожения, повреждения. В сфере эмоциональных переживаний данный этап выражает семантику беспокойства, причинения досады, вреда. Кроме того, процесс приобретения знаний в метафорическом плане воспринимается носителями русского языка также в ракурсе дробления еды.

2. Этап проглатывания. Второй этап, т. е. глотание, связан с прохождением пищевого кома из полости рта в глотку, а затем в пищевод. Несмотря на сложность самого процесса глотания, который включает в себя координацию многих мышц и органов, в человеческом сознании отражаются специфические эффекты осмысления человеческой активности. Семантику данного этапа маркирует глагол-идентификатор глотать. Согласно лексикографическим данным, глотать - значит 'движением мускулов горла проталкивать что-н. через пищевод’ (TSRÂ 123). В переносном плане общий смысл глагола концентрируется вокруг выражения значений принятия, допущения, разрешения, прохождения, т. е. концептуализация объекта наступает в рамках замкнутых частей пространства, так как имеется в виду переход из одного пространства в другое. В результате переноса активизируются значения пря-

2 В связи с этим ср. также синонимический фразеологизм попасть на язык кому 'становиться предметом разговора, обсуждения, пересудов' (FSRÂ 342). 
тания, подавления. Такое значение реализуется в выражениях: проглотить (горькую) пилюлю 'молча, терпеливо выслушать что-нибудь неприятное, перенести оскорбление', глотать слезы 'подавлять рыдания'. Следовательно, процесс сдерживания отрицательных эмоций передается как процесс их проглатывания.

Кроме того, в русском языке функционируют и другие устойчивые сочетания с изучаемым глаголом, ср.: проглотить оскорбление (обиду, упрек) 'смолчать, не отвечать на оскорбление'. Ср. также фразеологизм точно муху проглотил в значении 'недоволен, имеет кислый вид’ (FSRÂ 361). В данном случае у основ состояния настроения присутствует слово муха, которое концептуализируется как причина возникновения определенного настроения. Объект глотания представлен как эмоции, а желудок - в качестве „контейнера”, места укрытия этих эмоций. Фразеологизм глотать слюнки также в ряде контекстов имеет зачастую негативные коннотации со значением 'с завистью, вожделением смотреть на что-либо заманчивное, соблазнительное, но недоступное’ (FSRÂ 108).

Человеческий опыт показывает, что ощущения от нахождения в горле чужеродных предметов концептуализируются как дискомфортные. Такое ощущение стало плодотворной почвой для возникновения новых смыслов. Примером этому может послужить просторечный фразеологизм застревать (застрять) в горле у кого со значением 'оставаться невысказанными, недоговоренными (о словах, упреках и т. п.)' (FSRÂ 170). Разговорное выражение проглотить язык со значением 'замолчать, перестать говорить, болтать и т. п.' (FSRÂ 361) остается в тесной связи с речевыми процессами: отсутствие языка (его глотание) делает невозможным осуществление речевой деятельности.

Другая конструкция как кость в горле (кто, что, кому) со значением 'сильно надоесть, раздражать (обычно о человеке)' выражает также отрицательную оценку и является отражением человеческого опыта, так как наличие чужеродных предметов в горле естественным образом также вызывает дискомфорт. Исключительно важное место отводится горлу. Данная лексема употребляется и в других фразеологизмах, ср.: стоять (стать) колом в горле (в глотке) в значении 'очень надоедать, досаждать, мешать кому-либо, раздражать кого-либо’ (FSRÂ 459) или разговорное становиться (стать) поперек горла. Как уже отмечалось, наличие чего-либо в горле вызывает неприятные ощущения, мешающие правильному функционированию организма, что является плодотворной почвой для возникновения переносного смысла. Этот вполне реальный человеческий опыт переносится в абстрактную сферу человеческих взаимоотношений и активизирует значение 'сильно мешать кому-либо'. Вероятно, что в данном случае горло концептуализируется как 
путь или дорога по образцу устойчивого выражения становиться (стать) поперек дороги (пути).

В современном русском языке процесс глотания осмысляется отрицательно и в других переносных употреблениях глагола, например глотать в значении 'задержать, погубить': У меня карту проглотил банкомат. Идентичное значение имеет также глагол зажевать что-либо, хотя, учитывая семантику глагола, данное выражение следует отнести к первому этапу, т. е. к начальной стадии systema digestorium, так как глагол зажевать несет значение 'начать жевать' (NSRÂ I, 486). В свою очередь, в контексте зажевать кассету глагол получает значение 'испортить'.

Процесс освоения чего-либо, ознакомления с чем-либо может также концептуализироваться человеком в ракурсе перехода пищи в желудок. В таком случае наподобие глотания еды выступает принятие, освоение чего-либо. Такая метафора реализуется во фразеологизме глотать книги со значением 'разг. читать быстро, залпом' (TSRÂ 132). Лексикографические источники подчеркивают количественную и обстоятельственную характеристики, ср.: 'читать быстро, много, без разбору’ (NSRÂ 314). Таким образом, процесс глотания осмысляется как освоение объекта действия, а в случае анализируемого словосочетания - 'того, что прочитано'. Отражение понятийной метафоры отчетливо наблюдается в предложении: $A$ Bbl ,глотаете” или медленно перевариваете книги? В данном предложении процесс глотания и переваривания проецируется на познавательную сферу человека, которая реализуется на уровне процесса чтения. Структура метафорических моделей возникла естественным образом в человеческом сознании на базе сравнения чтения (процесса „принятия” информации) с процессом потребления, „принятия” пищи. В связи с этим на данном примере представим соотношение элементов структуры:

$\begin{array}{lll}\text { глотание } & \rightarrow & \text { быстрое чтение } \\ \text { переваривание } & \rightarrow & \text { медленное чтение, осмысление } \\ \text { продукт питания } & \rightarrow & \text { книга, содержание книги }\end{array}$

Дифференциация глотания и переваривания по темпоральному признаку (противопоставление по краткости/длительности действия) отражает физиологический опыт человека, так как глотание воспринимается как кратковременное действие, в противоположность перевариванию, которое понимается как более продолжительный процесс. Следовательно, в домене-цели сохраняется временная составляющая этих действий, а сам процесс чтения представлен в концептуальной метафоре в качестве еды, проходящей через пищеварительную систему.

3. Этап переваривания. Данный этап заключается в превращении сложных пищевых веществ, под воздействием ферментов, вырабатываемых органами пищеварительной системы, в более простые соединения. Поэтому 
базовым для данного этапа становится глагол переваривать - 'подвергать процессу пищеварения’. Семантика глагола, в основе которого лежит „процесс усвоения", также проецируется на ментально-интеллектуальную сферу деятельности человека. Концептуализация мыслительных процессов в данных рамках опирается на том факте, что человек конструирует свои абстрактные представления, базируясь на материальных элементах или физических (внутренних) процессах, происходящих в организме человека. Поэтому вполне возможным оказывается осмысление пищеварительных процессов в области мыслительно-речевой активности. Приведем примеры такой метафоризации: Я умолкла, переваривая полученную информацию; Она промолчала, переваривая сообщение; Это можно исправить, только если начать переваривать его немедленно. Таким образом, метафора, построенная по образцу „думать (усваивать, воспринимать) - это переваривать”, возникает на базе складывающегося сравнения сенсорно-моторного процесса переваривания (структура „источника”) с абстрактным процессом мышления (структура „цели”). Структура цели получает структуру источника в результате метафорической проекции. Одновременно у основ процесса метафоризации лежит наличие общего темпорального показателя в структуре источника и цели, что непременно облегчает сам процесс проекции.

Следует отметить, что процессы человеческого мышления в высокой степени метафоричны. Значение глагола переваривать встроено также в иные концептуальные сферы. Присмотримся к выражению не переваривать друг друга, ср.: Они настолько не переваривали друг друга, что никогда и ни о чем не могли договориться, даже если от этого страдали их собственные интересы; Меня от них тошнило, и почти все мои ребята с трудом переваривали таких людей, они не могли воспринимать их всерьез. В данной метафорической проекции ментальные процессы „взаимопонимания” структурируются по образцу источника, т. е. процессов переваривания. Глагол переваривать в сочетании с отрицательной частицей не получает следующее разговорное значение: 'очень не любить, не выносить кого-, чего-либо' (BTSRÂ 795).

Кроме прочего, процессы переваривания пищи происходят в кишечнике. Возможно поэтому данная часть организма человека переосмысляется, базируясь на физиологических свойствах кишок (их длине и эластичности) (Guancze 200), например: вымотать все кишки 'замучить', вырезать кишки 'убить'. Данный орган концептуализируется как жизненно важный, а применение в отношении кишечника насилия приводит к отрицательным последствиям (смерти). О том, насколько важную функцию играет данный орган в ментальной репрезентации человека, свидетельствует, например, кишка тонка в значении 'кому-либо не хватает сил, таланта, 
способностей, чтобы сделать что-либо'. Следовательно, этот орган воспринимается в русской лингвокультуре как сосредоточие жизни и силы. Следует отметить, что главный процесс пищеварения происходит в желудке, однако в русском языке фразеологизмы с компонентом желудок отсутствуют (Guancze 201).

4. Этап дефекации. Последний этап охватывает действие с базовым глаголом-идентификатором испражниться. Согласно Большому толковому словарю русского языка лексема испражниться имеет значение 'освободить свой кишечник от кала' (BTSRÂ 402). Данное действие выражают также синонимы типа вылелять, опорожнять и вульг. срать. Отметим, что фразеологизмы с глаголом испражниться отсутствуют в русском языке. Зато исключительную активность в просторечной и жаргонной речи проявляют устойчивые выражения с глаголом срать и существительными жопа, говно. Как правило, во многих культурах, в том числе и русской, все, что связано с физиологией, в том числе с дефекацией, является табу в рамках коммуникативного общения. Как пишет Наталия Ивановна Замерченко,

табуированность данной темы предположительно связана с тем, что определенные части человеческого тела и функции, которые они выполняют, являются частью человеческого „Я”, представляя сакральную область человеческих знаний (Zamerčenko 7).

Глагол срать концентрируется вокруг значений с крайне негативной окраской. Согласно Словарю современной лексики, жаргона и сленга одним из значений глагола срать является 'критиковать в жесткой форме, оклеветать' (SSLŽS). Приведем экземплификации: Зачем ты сразу мою идею обосрал? Теперь видишь же, что я был прав; Ничто так не объединяет, как возможность вместе кого-то обосрать; Он обосрал меня, потому что мне нравится , мальчишеская" игра! Но многие девочки в нее играют! В жаргонной и просторечной речи значение глагола очень широко и может выражать также отрицательно-пренебрежительное отношение, отсутствие заинтересованности к кому-либо, к чему-либо. Оно синонимично глаголу игнорировать или плевать, ср.: Мне срать, что он знал, а чего не знал; Срать я хотел на эту вашу упячку.

Некоторые словари фиксируют также ряд выражений, в которых на первый план выдвигается семантика презрения. Такие фразеологизмы имеют вульгарный и просторечный оттенки, ср.: срать (насрать) на голову (кому) со значением 'абсолютно не считаться с кем-л., делать кому-л. гадости, пакости'; срать я хотел с высокой елки 'выражение крайнего презрения, безразличия к кому-, чему-л.' (SRB 311). 
Значение данного глагола может актуализироваться в зависимости от контекста, в котором объект действия наделяется отрицательным оценочным оттенком.

Это позволяет расширить переносное значение глагола на различные сферы, в которых необходима негативная характеристика объекта действия. В зависимости от контекста глагол получает новое значение, ср.: Tы мне все выходные обосрал!; У метро купил еще пива, сидел на скамейке, пил, злился на мудака, который обосрал мне весь день своими звонками в дверь...; Одно мое слово - и тық... Но я сегодня добрый, хоть ты и обосрал мне настроение; Сбербанк обосрал мне утро понедельника и выбил из колеи [...]. Банк отказал в проведении онлайн-платежа. В приведенных предложениях реализуется значение 'портить, мешать кому-либо'.

Кроме того, электронный Энииклопедический словарь фиксирует глагол обосрать в значении 'опозорить, опорочить кого-, что-л.' (ЀS). Данное значение возникло на базе прототипических жизненных ситуаций, связанных с тем, что некоторые физиологические потребности человека лежат в сфере интимности, табу, поэтому данная сфера стала плодотворной почвой для появления семантики 'позора'. Следует вспомнить еще другой префиксальный глагол - просрать, который в русском языке в переносном употреблении выражает: 1. 'потратить, истратить попусту', 2. 'проиграть, остаться в проигрыше'. Из представленного вытекает, что глагол в целом выражает семантику отрицательных результатов, последствий, о чем свидетельствуют прочно укрепившиеся в жаргонном языке коллокации: просрать дело, просрать бизнес, просрать жизнь и т. д. Второе значение чаще всего реализуется в речи болейщиков, спортсменов, ср.: Уткин о „Матч ТВ”: Они просрали чемпионат Англии, и я несказанно рад. Уровень управления-ниже плинтуса; Далее в матче с Германией „отличился” Видич, но немиы благополучно просрали пенальти (и, как оказалось, весь матч).

В ментальном пространстве русского народа переживание сильного страха также связано с данным процессом. Такая концептуализация имеет свои корни непосредственно в физиологии и психологии человека. Согласно медицинским исследованиям, в ситуации сильного страха, испуга кишечник опорожняется непроизвольно, что является естественным инстинктом. Следовательно, такие глаголы, как обосраться, обкакаться, в переносном смысле имеют значение 'испугаться; испытать сильный страх'. Впрочем, интересно, что такое же значение несут другие глаголы физиологического действия, которые употребляются переносно: обоссаться, обмочиться, описаться. Приведем примеры: Он же, извините, полностью обосрался. Во всех смыслах. Революиию он совериил, власть захватил, Россию перевернул, но для чего?; Что, обосрался сын кулаикий? Ничего, и твое время придет. 
Да, сегодня как-то совсем сильно...; У сборщика Сидорова, устанавливающего заряд на атомную бомбу, дрогнула рука. Никто этого не заметил. Поэтому обосрался только он.

Таким образом напрашивается вывод, что каждый этап пищеварения имеет свою специфику и концептуализируется в определенных рамках видения мира. Первый этап, связанный с измельчением, раздроблением продуктов на мелкие части, часто концентрируется на значениях беспокойства (угрызения совести), атаки (грызть глотку), учебы (грызть гранит науки), освоения (разжевать и в рот положить), объекта сплетен (попадать на зубок), причинения досады и ряда других значений. Этап проглатывания в русской лингвокультуре осмысляется в рамках семантики перенесения оскорбления (проглотить пилюлю), зависти (глотать слюнки), молчания (проглотить язык), раздражения (как кость в горле), задержания (проглотить карту), чтения (глотать книги) и др. Некоторые типы этого переноса функционируют в рамках метафоры пространства. Этап переваривания связан с наличием темпорального показателя и концептуализируется в ментально-интеллектуальной сфере деятельности человека, которая отражает довольно продолжительные по времени умственные процессы (напр. переваривать информачию). Кроме того, данный этап сосредоточивается на выражении семантики вражды (не переваривать друг друга), смерти (вырезать кишки), мучения, страдания (вымотать все кишки). Следует отметить, что метафора systema digestorium в русском лингвокультурном пространстве используется для передачи выразительности и оригинальности речи. В частности, последний этап - дефекация - отличается высокой образностью и экспрессивностью, и поэтому чаще всего принадлежит жаргонной и вульгарной речи. Этот этап активизирует отрицательный круг значений, связанных с критикой (обосрать идею), пренебрежительным отношением (срать с высокой елки), неудачей (просрать жизнь), а также страхом (обосраться, обкакаться). В заключение следует подчеркнуть, что перспективным представляется изучение метафор systema digestorium в сравнительном плане с другими языками, что позволит выделить сходства и различия в лингвокультурном пространстве разных языков.

\section{Библиография}

Guancze, Čžèn. Frazeologizmy s komponentom „organy brûšnoj polosti” v russkoj i kitajskoj lingvokul'turah. Web. 02.11.2019. http://scjournal.ru/articles/issn_1997-2911_2015_10-1_48. pdf.

Kubrâkova, Elena S. Âzyk i znanie. Na puti polučeniâ znanij o âzyke: časti reči s kognitivnoj točki zreniâ. Rol' âzyka v poznanii mira. Moskva, Âzyki slavânskoj kul'tury, 2004. 
Lakoff, Džordž, Mark Džonson. Metafory, kotorymi my živem. Moskva, Izdatel'stvo Editorial URSS, 2004.

Maslova, Valentina A. Lingvokul'turologiâ: učebnoe posobie dlâ studentom vysših učebnyh zavedenij. Moskva, Akademiâ, 2001.

Tokarski, Ryszard. Światy za stowami. Wyktady z semantyki leksykalnej. Lublin, Wydawnictwo Uniwersytetu Marii Curie-Skłodowskiej, 2013.

Zamerčenko, Nataliâ I. Kommunikativnye tabu v nemeckoj i russkoj lingvokul'turah. Web. 12.04.2021. https://cyberleninka.ru/article/n/kommunikativnye-tabu-v-nemetskoy-i-russkoy-lingvokulturah/ viewer.

Zueva, Tat'âna A. Čelovek skvoz' prizmu artefaktnoj metafory v russkoj idiomatike. Web. 23.07.2019. https://cyberleninka.ru/article/v/chelovek-skvoz-prizmu-artefaktnoy-metafory-v-russkoy-idiomatike.

\section{Список сокращений}

BTSRÂ - Kuznecov, Sergej A., red. Bol'šoj tolkovyj slovar' russkogo âzyka. Sankt-Peterburg, Norint, 1998.

ÈS - Ènciklopedičeskij slovar'. Web. 02.11.2019. https://dic.academic.ru/contents.nsf/es/.

FSRÂ - Molotkov, Aleksandr I., red. Frazeologičeskij slovar' russkogo âzyka. Moskva, Russkij âzyk, 1978 .

NKRÂ - Nacional'nyj korpus russkogo âzyka. Web. 05.11.2019. http://www.ruscorpora.ru/new/.

NSRÂ - Efremova, Tat'âna F. Novyj slovar' russkogo âzyka. Tolkovo-slovoobrazovatel'nyj. T. 1-2. Moskva, Russkij âzyk, 2000.

SRA - Elistratov, Vladimir S. Slovar' russkogo argo (materialy 1980-1990-h gg.). Moskva, Russkie slovari, 2000.

SRB - Mokienko, Valerij M., Tat'âna G. Nikitina. Slovar' russkoj brani, matizmy, obscenizmy, èvfemizmy. Sankt-Peterburg, Norint, 2003.

SSLŽS - Slovar' sovremennoj leksiki, žargona i slenga „SLOVONOVO”. Web. 02.11.2019. http://www. slovonovo.ru/.

TSRÂ - Ožegov, Sergej I., Nataliâ Û. Švedova. Tolkovyj slovar' russkogo âzyka. Moskva, Azbukovnik, 1997. 